\title{
UN PROMOTOR DE LA ENSEÑANZA AGRÍCOLA DESDE LA REAL SOCIEDAD ECONÓMICA MATRITENSE: ANTONIO SANDALIO DE ARIAS (1809-1820)
}

\author{
Rolando E. Misas Jiménez \\ Centro de Estudios de Historia y Organización de la Ciencia Carlos J. Finlay Academia de Ciencias de \\ Cuba, La Habana
}

\section{RESUMEN}

La enseñanza agrícola en España durante el primer tercio del siglo XIX estuvo vinculada a la labor de Antonio Sandalio de Arias. La Real Sociedad Económica Matritense fue el escenario donde desde 1809 difunde sus enseñanzas. Arias encontró en esta sociedad ilustrada el vehículo idóneo para su propósitos docentes, debido a la influencia que ejercía sobre las restantes sociedades de Amigos del País y a su buena relación gubernamental. El interés de Arias por la enseñanza de la agricultura desde la Real Sociedad Económica Matritense es el argumento de nuestro estudio.

\section{SUMMARY}

The agricultural teaching in Spain during the first third of the XIX century was bonded to the work of Antonio Sandalio de Arias. The Matritense Royal Economical Society was the stage where since 1809 spreads his teachings. Arias found the suitable vehicle for his educational purposes in this Enlightened society, due to the influence which exerted on the remaining Societies of Friends of the country and to its good government relationship. The interest of Arias for the teaching of the agriculture on the Matritense Royal Economical Society is the argument of our study.

\section{INTRODUCCIÓN}

No se puede hablar de la enseñanza agrícola en España en el primer tercio del siglo XIX sin mencionar a Antonio Sandalio de Arias y Costa. Nacido en Madrid el 3 de septiembre de 1794, su fama trascendió desde la Real Sociedad Económica Matritense gracias al esfuerzo que realizara desde 1809 por extender la enseñanza agrícola en la península. Con la distinción de Socio de Mérito Literario de la Matritense, obtenida en 1808 por su Cartilla de Agricultura, Arias encontró en esa institución ilustrada el vehículo más idóneo para encauzar su propósito de institucionalización do- 
cente, debido a la relativa influencia centralizadora que poseía sobre las restantes sociedades de Amigos del País y a su relación con el gobierno. De hecho, compartió los criterios que conservaban reformistas moderados como Esteban y Claudio Boutelou con respecto a la estructura y a la legislación agrarias. Esos criterios debieron predominar en la Matritense en el período que estudiamos ${ }^{1}$, concediéndole a esta institución un papel activo en la educación agrícola de los labradores propietarios. A ese interés de Arias por la promoción de la enseñanza agrícola desde el contexto de la Real Sociedad Económica Matritense le prestaremos atención, agradeciendo el apoyo recibido en esa venerable institución en la consulta de sus fondos documentales.

INTENTO DE ARIAS POR PROMOVER LA ENSEÑANZA DE LA AGRICULTURA EN LAS PROVINCIAS DE ESPAÑA DURANTE LA OCUPACIÓN FRANCESA (1809 - 1811)

\section{El afrancesamiento de la Real Sociedad Económica Matritense: su apoyo a José Bonaparte}

A pesar de la presencia del ejército francés, la Real Sociedad Económica Matritense mantuvo en gran medida la continuidad de sus tareas durante el mando militar de Murat y el reinado de José I. El período que se inicia con la reinstalación del rey Bonaparte en Madrid, en octubre de 1809, debió ser mucho más estable para la Sociedad debido al apoyo directo de los funcionarios del nuevo monarca. A instancia del entonces Ministro del Interior, Manuel Romero, el rey manifestó el 7 de octubre su deseo de que se reorganizara la Sociedad, gestión que llevaron a efecto el marqués de Almenara y Carlos Montargis sin que ostentaran el título de director. De hecho, los españoles afrancesados asumieron las funciones más importantes dentro de la Sociedad: la dirección fue, en definitiva, ocupada el 27 de noviembre de 1810 por el marqués de Almenara, Ministro del Interior desde principios de enero de 1810; le siguió en ese puesto, el 14 de diciembre de 1811, Manuel María Cambronero quien desempeñaba la Secretaría de Estado con el rey francés y, por último, el 16 de enero de 1813, se hizo cargo de esa responsabilidad Claudio Boutelou -director del Real

1 Como ejemplos de ese moderantismo se pueden citar los «Apuntes sobre varios vicios de la legislación vigente con respecto de la Agricultura» que leyera el 23 de septiembre de 1811 el subdirector de la Sociedad Económica Claudio Boutelou, mientras que su hermano Esteban - catedrático de Agricultura y de Economía rural en el Jardín Botánico- había disertado en los días 2, 9 y 23 de marzo de ese mismo año sobre «Algunos estorbos de nuestra Agricultura» (Demerson, G. (1969), «La Sociedad Económica Matritense en tiempo de José I» Boletín de la Real Sociedad Bascongada de los Amigos del País, año XXV, cuaderno $\left.\mathrm{I}^{\circ}, \mathrm{pp} .52-53\right)$. 
Jardín Botánico de Madrid- quien había estado fungiendo como subdirector de los Amigos del País desde $1811^{2}$.

El colaboracionismo de la Real Sociedad Económica con la monarquía bonapartista alcanzó su máxima expresión con la recepción que José I le brindó en Palacio el 22 de mayo de 1812 a una numerosa comisión del Cuerpo Patriótico presidida por Cambronero. En la «Relación de las tareas de la Real Sociedad Económica de Madrid» que el Secretario Antonio Siles le leyera al rey se expresa la constancia con que la institución trabajaba:

«La Real Sociedad Económica de Amigos del País de esta corte, (...) no se ha desentendido un momento de tan sagrados deberes en la presente época a pesar de las calamidades y turbulencias que por desgracia agitan la nación; encargada de fomentar la Agricultura, de avivar la Industria y de perfeccionar los oficios y artes mecánicas, no se ha entibiado ni aún por breves instantes su infatigable y desinteresado celo en alentarlos todos, desde la feliz exaltación de V.M. a el trono de España» ${ }^{3}$.

Luego del discurso del Secretario Antonio Siles y de la entrega al rey de seis tomos de las Memorias de la Sociedad, José I señaló que «le eran muy gratas las ocupaciones de la Sociedad en medio de los desastres de la guerra y la revolución (...) que tenía a bien se inscribiera su nombre al frente del Catálogo de los individuos de este cuerpo patriótico... $\rangle^{4}$. Hasta ese momento -octubre de 1812 - los afrancesados habían confiado en la viabilidad de una monarquía bonapartista para establecer reformas de carácter moderado en la estructura agraria de España. Dentro de las posibilidades que le brindó la guerra al gobierno de José I, gran interés debió despertar en los integrantes de la Sociedad Económica algunas medidas encaminadas a beneficiar a los campesinos: en noviembre de 1809 los corregidores e intendentes recibieron circulares del gobierno para que vigilaran de cerca las labores agrícolas con vista a garantizar la subsistencia. Sin embargo, mayor alcance debieron tener los Decretos de 23 de mayo y de 1 de septiembre de 1809 que adjudicaban en arriendo las tierras sobrantes de los Sitios Reales de Aranjuez y de San Fernando. En ese contexto,

2 GonzÁlez Echegaray, C. (1993), «Vínculos de la Matritense con la Corona de España», en Torre de los Lujanes, Boletín de la Real Sociedad Económica Matritense de Amigos del País, $\mathrm{n}^{\circ} 25,3^{\circ}$ $4^{\circ}$ trimestre, pp.178-180.

3 Demerson, G. (1969), «La Sociedad Económica Matritense en tiempo de José I», en A. del Valle y Lersundi et al., La Real Sociedad Bascongada y la llustración, Boletín de la Real Sociedad Vascongada de los Amigos del País, San Sebastián, año XXV, cuaderno $1^{\circ}$, pp.48-49.

4 GONZÁlEZ ECHEGARAY, C. (1993), p. 179. 
también fue de gran importancia el Real Decreto de 17 de abril de 1810 que revitalizaba el asentamiento poblacional en Sierra Morena y en Andalucía ${ }^{5}$.

Sin embargo, las primeras reformas de José I encaminadas a solucionar la situación agraria de las regiones que se hallaban bajo su jurisdicción debían ser complementadas con la extensión de la enseñanza agrícola a esos territorios ya que, hasta entonces, esa actividad docente había recaído en el Real Jardín Botánico de Madrid a través de la cátedra que regentaba Esteban Boutelou desde 1807. De hecho, el rey bonapartista había mostrado su interés en propiciar el desarrollo de esa enseñanza en el Jardín Botánico ${ }^{6}$, y por tanto, debía estar inclinado a favorecer su extensión hacia otras regiones de la península aunque no se adoptara ese modelo de institución docente.

De esa forma, se creaban las condiciones para que Antonio Sandalio de Arias se preocupara, en septiembre de 1809, por presentar su proyecto de Escuelas de Agricultura.

Antonio Sandalio de Arias y su «Discurso para la formación de un plan de Escuelas de Agricultura $»(1809)$

Imbuído de la esperanza que le proporcionaba el gobierno de José I, Arias presentó en Junta de la Sociedad Económica Matritense del 9 de septiembre de 1809 su «Discurso para la formación de un plan de Escuelas de Agricultura» ${ }^{7}$.

5 Mercader Riba, J. (1983), José Bonaparte Rey de España (1808-1813). Estructura del Estado Español Bonapartista, CSIC, Madrid, pp.413-417.

6 Como reflejo de ese interés, José I decretó el 18 de febrero de 1809 la inmediata distribución de los terrenos, que procedentes de la huerta del Convento de los Jerónimos y de la corta porción que mediaba entre aquélla y el Observatorio del Retiro, debían ser utilizados para el establecimiento «de las escuelas prácticas y de observación indispensables para enseñar por el libro de la Naturaleza, la agricultura y la economía rural, dando luego principio al de las plantas». El traslado del botánico - de orígen colombiano- Francisco A. Zea como jefe de división del Ministerio del Interior no significó una actitud indiferente del gobierno hacia la institución botánica ya que en su puesto de director del Jardín lo sustituyó el segundo profesor y jardinero mayor, Claudio Boutelou, mientras que su hermano Esteban pasó a ser el nuevo segundo profesor desde su plaza de catedrático de Agricultura y Economía rural. A pesar de las dificultades financieras del gobierno y de algunos excesos de los soldados franceses, los hermanos Boutelou mantuvieron las lecciones públicas de Botánica y de Agricultura en el Jardín como lo indicaba la Gaceta de Madrid al anunciar el comienzo de las mismas el 11 de abril de 1812 y el 12 de mayo de 1813. Véase MerCAder RiBA, J. (1983), pp.543-544.

7 En el Archivo de la Real Sociedad Económica Matritense no se encuentra depositado el «Discurso» de Arias, al quedar en poder del auutor (leg.206, expte.19). El ejemplar que hemos consultado se localiza en el archivo del Real Jardín Botánico de Madrid, donde fue depositado por Arias, e indica erróneamente la fecha de su presentación en la Sociedad Matritense (I, 23, 2, 16). 
Aunque Arias no lo menciona suponemos que el recuerdo de las Escuelas de Agricultura que surgieron en diversos lugares de la península a finales del siglo XVIII debieron servirle de base para su proyecto.

En dos de las poblaciones españolas más importantes, Zaragoza y Valladolid, las Sociedades Económicas habían fundado escuelas de enseñanza agrícola. La de Zaragoza se supone que fue inaugurada entre los primeros años de la década de $1780 \mathrm{y} \mathrm{el}$ año 1789. Por su parte, la Escuela de Agricultura del reino de Aragón ya era una realidad en diciembre de 1780 cuando un activo miembro de su Sociedad, Ramón Amat y Mauleón de Osorio, presentó el «Diálogo de Agricultura para la Escuela de este arte en la Real Sociedad Económica Aragonesa de Amigos del País». La actividad de esta Escuela fue de gran interés para la época ${ }^{8}$. También surgieron Escuelas en poblaciones de menor categoría, como la de Pedreguer que pertenecía entonces a Valencia y que fue promovida por un grupo de prominentes vecinos con la mediación de la Sociedad Económica Valenciana ${ }^{9}$

Estas circunstancias demostraban que las Sociedades Económicas podían ser los mecanismos ideales para llevar a efecto el proceso de institucionalización de la enseñanza agrícola en la península. De hecho, se reconocía la necesidad de que ese tipo de enseñanza adquiriera personalidad propia adoptando un modelo de institución que no dependiera de la existencia de jardines botánicos. Esto no significaba que se negara la relación estrecha de trabajo que debía existir con la Cátedra de Agricultura que dirigía Esteban Boutelou en el Real Jardín Botánico de Madrid.

En su «Discurso», Arias asignaba a las Sociedades Económicas de las provincias la importante función de dirigir las cátedras de Agricultura que se establecieran en sus respectivos territorios a través de una Junta de Dirección nombrada a ese efecto.

8 Así lo indicaba el secretario del Consejo de Castilla, Pedro Escolano de Arrieta, el 12 de febrero de 1783 cuando alentaba a la Sociedad a que mantuviera la Escuela Rústica de Agricultura. También en la Gaceta de Madrid se informaba sobre los premios concedidos a los alumnos o la relación de los exámenes realizados. A partir de 1795, aparece mencionada como escuela o cátedra y en las Actas de la Sociedad Aragonesa del 10 de noviembre de 1797 se señala el nombramiento del doctor en medicina, Serapio Sinués, para que fuera su catedrático. Mallol Ferrándiz, J. (1991), «Un caso de irradiación de la Real Sociedad Económica de Amigos del País de Valencia: La Escuela de Agricultura de Pedreguer», en Molas Ribalta, P. (ed) (1991), La España de Carlos IV, Actas de la I Reunión Científica de la Asociación de Historia Moderna, Madrid. Durante la ocupación napoleónica esa escuela no existía: el 30 de marzo de 1809 se le comunicaba a José I que la Real Huerta y Ribera de Valladolid, concedida para experimentos de agricultura a la Real Sociedad Económica, se hallaba en estado deplorable y próximo a su total ruina (Mercader Riba, J. (1983), pp.443-444).

9 Esta Escuela comenzó a funcionar en noviembre de 1792 luego que los ilustrados lugareños le hicieran llegar el 14 de de septiembre de 1791 a los Amigos del País de Valencia la «Instrucción para el establecimiento de una Academia de Agricultura práctica en este lugar de Pedreguer». Al parecer, la escuela se mantuvo viva hasta 1796 sin lograr el reconocimiento del rey por los trámites burocráticos (ibidem, pp.234-238). 
Convencido de que una parte de la realización de ese plan dependía de la gestión que efectuara la mencionada Junta, Arias le concedía las siguientes atribuciones:

- Sería la encargada de administrar los gastos y los ingresos de los fondos destinados a la Escuela que se hallarían depositados en la Tesorería de la Sociedad (entre esos gastos se encontraban los salarios del Jardinero Mayor o profesor de Agricultura quien sería además el director, el del ayudante del profesor, el del maestro de dibujo quien fungiría también como administrador, el del mozo de labranza, el del portero y el de los jornaleros. Otros gastos estarían dirigidos a adquirir las herramientas necesarias. Los alumnos no pagarían su matrícula ni percibirían salario pero debían costearse su sustento. En definitiva, los ingresos de la escuela dependerían de la venta de sus cosechas).

- A ella tendría que acudir, en su función de director, el Jardinero Mayor o profesor de Agricultura para atender los gastos de la Escuela. Este tendría que compartir su labor docente con las tareas de dirección (las operaciones de cultivo, venta de las cosechas, etc.).

- Estaría obligada a dar cuenta a la Sociedad del estado en que se encuentren los fondos de la Escuela depositados en la Tesorería.

- Sería la responsable de atender las solicitudes de matrícula y de admitir a aquellos jóvenes que supieran leer, escribir y contar, además de una buena conducta social. Asimismo, se ocuparía de la disciplina de los alumnos ya que decidiría los casos de expulsión propuestos por el profesor y los castigos «puramente correctivos» que debían ser aplicados atendiendo que el «maestro debe hacerse respetar por solo el amor y dulzura». Igual intervención tendría en caso de que algún jornalero fuera despedido por el profesor ${ }^{10}$.

De hecho, la Junta de Dirección nombrada por la Sociedad Económica llevaría el peso fundamental para velar desde el punto de vista administrativo y disciplinario por la buena marcha de la institución docente. A ella se subordinarían en esas gestiones el profesor de Agricultura y el administrador del establecimiento - el maestro de dibujo-quien estaría bajo la dependencia del profesor y de la Junta. El profesor o Jardinero Mayor sería el enlace directo entre la Escuela y la Junta.

La actividad docente en cada Escuela de Agricultura estaría fundamentalmente en manos del Jardinero Mayor, tratando de que existiera una uniformidad en cuanto al método y al contenido de las lecciones. Por eso, Arias recomendaba la confección de una obra que fuera útil para todas las Escuelas para de esa forma evitar «la arbitrariedad é interpretaciones de los maestros» sin llegar a obviar la necesidad de que las Sociedades Económicas le hicieran las variaciones pertinentes para «subvenir á las dificultades qe. precisamente ocurriran por razon de los diversos climas y tempera-

10) Archivo Real Jardín Botánico de Madrid, I, 23, 2, 16. 
mentos de las provincias en qe. se establezcan las escuelas». De acuerdo con ese criterio, Arias mencionaba el contenido temático que en su opinión debería ser contemplado por cada profesor de Agricultura, destacando en el mismo el estudio de las tierras por la clasificación adoptada por Cadet-Devaux, que fuera extractada por Simón de Rojas Clemente en el Semanario de Agricultura, y el estudio de las plantas cultivadas de acuerdo al orden que proporcionaba el sistema de Linneo. La identificación de cada planta debía hacerla el profesor de una manera didáctica:

\footnotetext{
«(...)se pondran targetas con el nombre bulgar y el latino; y si el nombre bulgar no fuere arreglado se añadira un tercero qe. será el mismo nombre botanico traducido á nuestro castellano» ${ }^{11}$.
}

Dada su condición de profesor, el Jardinero Mayor impartiría las lecciones o curso de Agricultura apoyándose en una parte teórica y otra práctica íntimamente relacionadas entre sí de acuerdo con el siguiente método de enseñanza:

\footnotetext{
«Las lecciones de teórica se daran en los días lunes, miercoles y viernes de cada semana no siendo festivos, y en los siguientes será la práctica de aquella lección, haciendo á los discípulos una referencia de lo mas importante qe. se explicó en la leccion teorica antecedente,y varias preguntas sobre la misma practica, para observar si lo comprendieron; enseñandoles de este modo á formar sinderesis y sacar consecuencias de ambos estudios» 12 .
}

En esa interrelación entre práctica y teoría, la primera tendría una mayor frecuencia de clases durante el curso:

«La leccion teorica se explicará en invierno desde las 6 hasta las 8 de la noche, y en verano desde las 10 á las 12 de la mañana pero la practica se hará diariamente y sin interrupcion bajo unas $[\mathrm{h}]$ oras arregladas para los discípulos» 13 .

La labor docente del Jardinero Mayor también sería compartida por otros tres empleados:

- El ayudante del Jardinero Mayor quien sería el encargado de seguir las orientaciones de éste en cuanto a la instrucción cotidiana de los alumnos en las operaciones prácticas y en el manejo de las herramientas. Sustituiría al profesor en caso de ausencia o de enfermedad; por eso también debía asistir a las lecciones teóricas. Tam-

11 Ibidem.

12 Ibidem.

1.3 Ibidem. 
bién vigilaría el trabajo de los peones y pasaría lista a los alumnos y jornaleros que asistieran a las jornadas de la mañana y de la tarde. Sería el responsable de las herramientas y utensilios de la escuela.

- El maestro de dibujo quien asumiría el propósito de enseñar, como parte de las lecciones teóricas, la geometría y planimetría con relación a la agricultura, esmerandose en la copia de máquinas, plantas, flores, etc.

- El mozo de labor, empleado en la enseñanza práctica del arado y de cualquier otro que se adopte bajo la indicación del profesor.

Sin embargo, ese no sería el principal obstáculo para que las Escuelas tuvieran un desempeño satisfactorio en sus tareas docentes. En la parte introductoria de ese plan, Arias señalaba haber dedicado algunos ratos de ocio al análisis de cómo favorecer el interés del labrador por las tareas agrícolas, y por ende, en la adquisición de los conocimientos agronómicos.

En su opinión no bastaba la presencia de sabios para fomentar la agricultura:

\footnotetext{
«Sus escritos diran como deben hacerse las maniobras del cultibo: enseñaran á conocer por sus caracteres las tierras buenas, las medianas y las inferiores; propagaran luces para variar de semillas prefiriendo estas á las otras: hablaran de los vicios de la labor, de los estorbos qe. impiden su adelantamiento, y de los medios qe. podian adoptarse para mejorarla; pero todo es poco, y así lo acredita la experiencia pues en el día despues de tantos escritores antiguos, y de nuestra edad, la Agricultura va decayendo» ${ }^{14}$.
}

Arias criticaba la legislación del Antiguo Régimen que justificaba los gravámenes onerosos que soportaban los labradores. Sustentaba su crítica en el principio liberal de que debía garantizarse el interés individual de los labradores con la concesión de una «justa libertad»:

«Yo entiendo por justa libertad - decía Arias - aquella proteccion qe. es debida al vasallo y á sus propiedades por la qual queda en su arbitrio disponer de sí y de sus cosas como le acomode no siendo en perjuicio del orden público y por interes la ganancia no prohivida dependiente de la justa libertad.

Estas nociones convencen que dejar en justa libertad el interes del Labrador no es sino tratarle con la consideracion qe. se merecen los individuos de todas las clases y conserbarle los derechos del hombre constituido en sociedad»15.

Para Arias era de vital importancia el respeto a la propiedad agraria; por eso consideraba necesaria la abolición de determinadas leyes y ordenanzas que habían sido

\footnotetext{
14 Ibidem.
}

15 Ibidem. 
impuestas por el Estado Absolutista. Ese era el deseo de un sector de los labradores propietarios. Así lo expresaba uno de ellos a través de Arias:

\footnotetext{
"Yo soy un miembro de la sociedad y prescindiendo de si mi profesion es el alma de aquella me contento con la proteccion debida á todo vasallo y sus cosas. El Estado tiene cargas ordinarias y extraordinarias. En las unas y las otras mi sudor y mi vigor estan prontos, pero pereceré y conmigo la Monarquía si no tiene en consideracion mis fuerzas para cargarme»16.
}

No obstante, Arias no se consideraba capaz de presentar un plan detallado que satisfaciera esa necesidad a pesar de que sugiere un censo de la población rural — propietarios y colonos - para la determinación de los arbitrios que debían ser legitimizados en cada provincia. La solución de este problema facilitaría mucho más el propósito señalado por Arias de establecer Escuelas de Agricultura en cada capital de provincia o en «qualquiera otro pueblo de ella si por su situacion, localidad y conveniencia fuese mas aproposito qe. la capital» 17

Cada Escuela debía tener una extensión de 50 fanegas, o sea de 2 millones de pies superficiales de tierra, de las cuales 9 fanegas (las dedicadas al huerto-jardín y al vivero de árboles) debían ser de regadío. Ese total de 50 fanegas debía dividirse en las siguientes porciones de tierra:

$I^{a}$ porción: Es el terreno de regadío de 5 fanegas destinado a la huerta-jardín que se distribuiría en 20 cuadros menores de 100 estadales cada uno, subdividido también en 10 canteros (cada cantero en 10 eras). Alrededor de cada cuadro debían plantarse árboles frutales de toda especie sin que perjudiquen a las restantes plantas. En ese terreno se cultivarían las hortalizas, las legumbres, los frutos comestibles y las plantas ornamentales que existían en los jardines de recreo. En opinión de Arias esta sería la porción de tierra que «presenta muchas ventajas para dirigir las lecciones prácticas, hermanadas con las de la teorica», además de que la misma tendría un propósito utilitario: la de vender sus hortalizas. De esa manera, a los discípulos se les enseñaría a aprender «el secreto del arte reducido á endulzar la fatiga con la recompensa».

$2^{\mathrm{a}}$ porción: Sería el vivero o almáciga de árboles de toda especie con 4 fanegas de tierras de regadío. Estaría ubicado a un costado de la huerta-jardín y se dividiría a su vez en 16 cuadros de a 100 estadales. Cada cuadro tendría 10 canteros y cada cantero en 10 eras.

$3^{a}$ porción: De 5 fanegas de tierra de secano que debían estar destinadas al plantío de olivos poniéndolos entre sí a la distancia de 40 pies para que se pueda cultivar

\footnotetext{
16 Ibidem.
}

17 Ibidem. 
entre ellos cereales y leguminosas. De esa manera, el labrador podía sacarle más ventajas al espacio que media entre las líneas de árboles.

$4^{\mathrm{a}}$ porción: Debía de ser de 3 fanegas de tierra de secano dedicadas a olivos y viñedos, estableciendo una sola línea de cepas de viñedos entre cada dos de olivos que debía indicársele a los alumnos para «su instruccion é inteligencia». La distribución de esas fanegas debía ser similar al del caso anterior.

$5^{a}$ porción: En 3 fanegas de tierra debían plantarse viñedos «graduando las distancias pa. su plantacion por la calidad y asiento del terreno; por el clima y por las consideraciones arriba expresados».

$6^{a}$ porción: Se trata de las restantes 30 fanegas de tierra de secano que se subdividirían «en varios pedazos menores y se destinarán para el cultivo de las plantas cereales y leguminosas, y para qualesquiera otra qe. convenga criar en ella, con arreglo al clima, situación y calidad de la tierra».

Arias consideraba que la distribución que había hecho de las tierras en su plan podía cambiar «quando la situacion y calidad del terreno lo pidiesen». Igualmente podía sufrir variación las plantas que se cultivaran en las Escuelas de acuerdo a las condiciones climáticas de cada provincia. Por esa razón señalaba lo siguiente:

\footnotetext{
«Bien sé qe. en algunas partes no se podran criar olivos por qe. el temperamento demasiadamente frio lo impida, pero en su lugar y bajo las mismas reglas se criaran Perales, Camuesos, Manzanos, Membrillos, Ciruelos, Nogales, Castaños, etc, todos los quales seran siempre de utilidad conocida y servirán al intento de la enseñanza. Las mismas advertencias se aplicaran á la vid, y respectivamente á todos los vegetales, dirigiendose por las reglas qe. daran despues»18.
}

Las discusiones en torno al «discurso» de Antonio Sandalio de Arias (octubre de 1.809 - agosto de 1811)

La presentación del «Discurso para la formación de un plan de Escuelas de Agricultura» en Junta de la Sociedad Económica Matritense del 9 de octubre de 1809 motivó que en la misma se acordara crear una Comisión evaluadora compuesta por cuatro personas: Ramón Risel y Josef Garriga, quienes no asistieron a la reunión, además de Josef Miguel de Alea y Josef María Celas y Muñoz que sí estaban entre los pocos asistentes. Esta Comisión preparó un informe, en el que no aparece la firma de Alea, con fecha de 23 de octubre de 1809, que fue escuchado en la Sociedad en Junta de 20 de enero de $1810^{19}$.

\footnotetext{
18 Ibidem.

19) Archivo Real Sociedad Económica Matritense. Libro de Actas de las Juntas Generales de los años 1809-1810.
} 
El informe de Risel, Garriga y Celas pretendía criticar con pocas palabras el proyecto presentado por Arias a pesar de la importancia tan relevante que tenía el mismo. Si bien es cierto que recomendaban formalmente el pensamiento de Arias por su utilidad, las críticas señaladas le restaban credibilidad al mismo. Fundamentalmente estuvieron dirigidas a cuatro aspectos:

- Consideraban que el plan de Arias contemplaba «demasiadas Escuelas de Agricultura las qe. resultarian si se estableciese una en cada Provincia, y aun sería mayor el número si las actuales Provincias se dividen en otras menores...»

- Tampoco consideraban necesario la enseñanza del dibujo y de aquellas partes de la matemática que proponía Arias porque esos conocimientos debían ser adquiridos por los alumnos en otros establecimientos antes de que ingresaran en las Escuelas de Agricultura.

- También sugerían como más ventajosa la participación que tuvieran los empleados en la venta de los productos agrícolas para no tener que pagarles un salario.

- Por último, calificaban de bueno el método de enseñanza y las lecciones propuestas por Arias aunque creían conveniente que se sujetaran las lecciones a un nuevo examen con el propósito de que hicieran un mayor hincapié en el «modo de repoblar los montes de arboles y de extender el cultivo de estos vegetales, sin hacer establecimiento qe. ni remotamente coartaje la propiedad».

En definitiva, los comisionados concluían su informe indicando que si se llevaba a efecto tan apreciable proyecto sería necesario hacerle «otras observaciones qe. a su juicio le harian mas ventajoso» ${ }^{20}$.

Dado el interés de los reunidos en la citada Junta del 20 de enero de 1810 por presentar al gobierno de José I el «Discurso» de Arias, se acordó que en la mayor brevedad posible los comisionados ampliarían sus observaciones al proyecto escuchando la opinión de su autor. El único de los comisionados asistente a la Junta, Ramón Risel, recogió de nuevo el informe y el proyecto de Arias $^{21}$.

A despecho del apuro de la Sociedad, transcurrió un año sin que la Comisión reelaborara un nuevo informe y sin que le diera una explicación a Arias por su demora. Por acuerdo de la Junta de la Sociedad del 9 de febrero de 1811 — que actuaba a instancia de las reclamaciones de Arias- Ramón Risel se veía obligado a declarar en la próxima reunión el estado de ese proyecto. Ya para entonces Arias debió tener en cuenta que su proyecto podía ser de utilidad a la Junta Consultiva de Instrucción Pública y Educación, creada en el Ministerio del Interior por Real Decreto de 28 de enero de 1811, ya que la misma estaba encargada de formar un Plan General de Edu-

Archivo Real Sociedad Económica Matritense, leg.206, expte.19.

21 Archivo Real Sociedad Económica Matritense, libro de actas de las Juntas Generales. Años 18091810. 
cación e Instrucción Pública ${ }^{22}$. En definitiva, el 16 de junio de 1811, el Secretario interino de la Clase de Agricultura le entregó a Claudio Boutelou el proyecto de Arias y el informe de Risel, Garriga y Celas para que lo examinara una Comisión de esa Clase. Ya el 24 de julio de ese año Claudio Boutelou informaba de los resultados del examen efectuado por esa nueva Comisión:

\footnotetext{
«Los establecimientos rurales para promover esta enseñanza son indispensables en el dia, en que la Agricultura ha dexado de considerarse como oficio, y en que se han empezado á reunir sus principios y elementos para formar un cuerpo de doctrina fundamental que sirva de base á este estudio.

Nos ha parecido que en lo general son apreciables y fundadas las ideas del autor, á pesar de que algunas de sus proporciones pueden ser tal vez equivocadas y que otras necesitan un maduro exámen para poderse admitir.

La Comision está persuadida de que las dos bases principales para la prosperidad y adelantamiento de nuestra agricultura son la proteccion de la propiedad y la enseñanza rural. Estas mismas ideas que ha adoptado en épocas anteriores nuestra Real Sociedad, los vuelve á reproducir el Sor Arias con nueva fuerza é interes.

(...) el plan de esta Memoria comprende muchos puntos indispensables para los progresos de nuestra Agricultura, y el autor habla con conocimientos y exactitud en todas las operaciones practicas del campo... $\rangle^{23}$.
}

Una voz autorizada como la de Claudio Boutelou le otorgaba al proyecto de Arias los méritos suficientes que justificaban su puesta en marcha a pesar de que ese no era el momento más oportuno para llevarlo a feliz término ${ }^{24}$. Así lo parece indicar el propio Boutelou cuando proponía que el proyecto de Arias se debía:

\footnotetext{
«(...)custodiar con señalamientos entre los qe. estan en el archivo de la Sociedad y tratan de este mismo punto, para consultarle si en algun tiempo se quisiese encargar alguno de sus individuos de formar un plan general de enseñanza agraria» 25 .
}

22 MerCader Riba, J. (1983), pp.530-531.

2.3 Archivo Sociedad Económica Matritense, leg.206, expte.19.

24 En esos momentos, urgía solucionar la hambruna que padecía el pueblo de Madrid como resultado de la guerra. A solicitud de la Sociedad Económica, el catedrático de Agricultura del Jardín Botánico, Esteban Boutelou, realizó investigaciones que le permitieron confeccionar una Memoria titulada «Sobre las plantas alimenticias que puedan reemplazar a la semilla del trigo en la elaboración del pan». Esta Memoria, acompañada de una tabla sinóptica o resumen, fue presentada a la Junta del 14 de diciembre de 1811 (Demerson, G. (1969), p.53). Con el título «De las sustancias vegetales que pueden servir para hacer pan» aparece publicado el trabajo de Boutelou en el Almacen de Frutos Literarios o Semanario de Obras Inéditas (Madrid, 1819, t.VIII, pp.68-120).

25 A.S.E.M., leg.206, expte. 19. 
Ese criterio de Boutelou recibió el respaldo de la Sociedad Económica en las Juntas del 27 de julio y del 5 de agosto de 1811. Esa decisión le había sido comunicada oficialmente a Arias el 3 de agosto ${ }^{26}$.

De esa forma, no se menciona más el proyecto de Escuelas de Agricultura de Arias hasta el 22 de mayo de 1812 en que se le notifica públicamente a José I el estado del mismo. El citado proyecto continuó archivado dada la grave situación en que se encontraba la monarquía bonapartista como consecuencia de las derrotas sufridas por el ejército francés. Esa situación provocó la evacuación definitiva de Madrid el 10 de agosto de 1812 y la penosa marcha de José I y su séquito hacia Valencia.

SEMEJANZAS Y DIFERENCIAS DEL PROYECTO DE ARIAS CON EL DECRETO SOBRE ESCUELAS DE AGRICULTURA DEL RÉGIMEN CONSTITUCIONAL (1813-1814)

El propósito de Arias de extender la enseñanza agrícola a toda la península coincidió con las aspiraciones de los liberales españoles que se enfrentaban a la intromisión francesa. Así lo indica la decisión tomada por las Cortes de Cádiz el 8 de junio de 1813 de crear en los pueblos principales, o por lo menos en todas las capitales de provincia, las Escuelas Prácticas de Agricultura. Esta enseñanza no se acondicionaba a la existencia de Jardines Botánicos en cada territorio.

A pesar de que ese decreto establecía igualmente la necesidad de que funcionaran las Sociedades Económicas ya existentes o las que hubiese que crear, en realidad no se les concedía el papel que con respecto a las Escuelas de Agricultura había previsto Arias en su proyecto de 1809. La disposición de las Cortes era muy explícita al señalar que «no ejercerán especie alguna de autoridad» con lo cual las excluía de toda gestión administrativa sobre la enseñanza agrícola provincial. Las funciones de las Sociedades Económicas se limitarían a:

\footnotetext{
«...la formacion de cartillas rústicas, acomodadas á la inteligencia de los labradores y á las circunstancias de los paises: á la produccion de memorias y otros escritos oportunos para promover y mejorar la agricultura y cria de ganados, y las artes y oficios útiles: á la publicacion y explicacion de los secretos y máquinas que puedan ser convenientes: á la distribucion gratuita de semillas y plantas que puedan aclimatarse: á proponer y distribuir públicamente algunos premios para excitar la aplicacion y la circulacion de luces(...)».
}

En otras palabras, las Sociedades Económicas estarían dedicadas a «ilustrar á las Diputaciones provinciales y ayuntamientos con sus observaciones en beneficio de

$$
26 \text { Ibidem. }
$$


estos ramos». Precisamente, a esas autoridades provinciales y municipales se les otorgaba el financiamiento de las Escuelas de Agricultura mientras que la Dirección General de Estudios sería la encargada de atender el plan de enseñanza. De hecho, las Sociedades Económicas quedaban excluídas de ejercer una acción directa sobre esas Escuelas mientras que la Sociedad Matritense debía concretarse a un ámbito provincial. Es así como el decreto pronunciado por las Cortes el 8 de junio de 1813 se diferenciaba del proyecto diseñado por Arias en 1809 cuando estaba al servicio de José I.

Una vez liberada Madrid de los franceses, los miembros de la Sociedad Económica que no huyeron hacia Valencia con José I mostraron su disposición de realizar las funciones que le otorgaba el mencionado decreto de las Cortes. Ese deseo tuvo dos momentos culminantes: la Matritense se reveló como ferviente admiradora de la Constitución de Cádiz el 31 de diciembre de 1813. Poco después, el 21 de enero de 1814 las Cortes recibieron a los delegados de la Matritense accediendo a una petición de ésta.

Uno de los primeros intentos de la Sociedad Económica por ponerse al nivel de las funciones que le atribuían las Cortes en la enseñanza agrícola se manifestó el 22 de noviembre de 1813 cuando su secretario, Antonio Siles, pidió a Claudio Boutelou que de acuerdo a lo tratado en la Junta del 20 de noviembre se hacía necesario que la Clase de Agricultura expresara «á la mayor brevedad posible la exposicion oportuna relativa á cátedras de Agricultura ${ }^{27}$. La Sociedad Económica Matritense podía aprovechar la tarea de asesoramiento que le había sido encomendada por el decreto del 8 de junio de 1813 para reclamar a su correspondiente Diputación Provincial la restitución de la cátedra de Agricultura del Real Jardín Botánico de Madrid, dada la ausencia del profesor Esteban Boutelou desde que se produjo la retirada de las fuerzas francesas ${ }^{28}$. Atendiendo la importancia que a nivel nacional tenía la mencionada cátedra, la Matritense (denominada entonces Real Sociedad Patriótica), envió una Representación el 11 de diciembre de 1813 a la Diputación Provincial con vista a que se dieran las órdenes oportunas para que «cuanto antes se abra la cátedra de Agricultura en el Jardín Botánico de esta Corte». No obstante, el silencio de la Diputación hacia una cátedra que se salía de su acción administrativa y del modelo de institución docente que estaba prescrito por la ley provocó que el 21 de abril de 1814 se tuviera que efectuar una petición similar a la Regencia del Reino ${ }^{29}$.

27 Archivo Real Sociedad Económica Matritense, leg.217, expte.7.

28 Esteban Boutelou nace en Aranjuez (Madrid), en 1776 y muere en 1814 en San Lúcar de Barrameda (Cádiz). Sobre su biografía véase López Piñero, J.Ma et al. (1983), Diccionario Histórico de la Ciencia Moderna en España, Ediciones Península, Barcelona, pp.127-128.

29 A.R.S.E.M., leg. 218 , expte.5. 
Sin embargo, la respuesta a cualquier intento de promoción de Escuelas de Agricultura estaría en manos de Fernando VII desde que propiciara el 4 de mayo de 1814 el restablecimiento del Absolutismo.

ESFUERZOS DE ARIAS POR HACER REALIDAD SU PROYECTO DE ESCUELAS DE AGRICULTURA DURANTE EL ABSOLUTISMO DE FERNANDO VI (1814-1815)

\section{Un acercamiento al tema: la propuesta de Regás}

Poco después del golpe de Estado de Fernando VII, la Real Sociedad Económica Matritense trataba de revitalizar las gestiones sobre la docencia agrícola. El 21 de mayo de 1814 se le pedía al Rey que volvieran a funcionar algunas de las instituciones docentes como la Cátedra de Agricultura del Jardín Botánico y que instalara asimismo otra cátedra de Enseñanza Agrícola en Alcalá de Henares. Todo parece indicar de que había la intención de que la primera — ubicada en el Jardín Botánico de la capital del Reino-, debía continuar impartiendo una docencia especializada al reunir material botánico procedente del resto de España y de Ultramar mientras que la segunda estaría en función de los intereses agrícolas de la provincia donde se asentaba Madrid. Su autor, el catalán Antonio Regás, señalaba lo siguiente:

«(...)la Sociedad que ha visto en 1807 establecerse en Madrid una cátedra de Agricultura teorica y practica no puede callar al ber suspensa esta enseñanza, mas al mismo tpo. que conoce la importancia y necesidad que hay de que V.M. la restablezca, no deve omitir que cree tambien de su obligacion se ponga otra en Alcala de Henares; ambos puntos el de esta Corte y el de aquella ciudad son mui aproposito pa. esta enseñanza; si en el $1^{\circ}$ el Jardin botanico establecido ya y enriquecido con un tesoro de plantas indigenas y exoticas proporciona la enseñanza mas completa en el centro de la capital; en el $2^{\circ}$ llama la atencion de la Sociedad los deliciosos terrenos de aquella campiña, sus frutos, sus aguas abundantes y desaprovechadas, todo pide instrucción en el cultibo, todo clama pr. enseñanza. Deja pues esta Provincia a V.M. este beneficio y empiece por aqui la grande obra de hacer a la nacion agricultora enseñandola tan interesante ciencia pa. q. saque de este fertilísimo y embidiado suelo la abundancia y riquezas que le estan consignadas» ${ }^{30}$.

El esfuerzo de la Sociedad Matritense por la Cátedra de Agricultura del Jardín Botánico se vio compensado de alguna manera con la Real Orden de 7 de junio de ese mismo año que satisfacía la Representación enviada a la Regencia al aprobar el establecimiento de la citada Cátedra a pesar de que no podía hacerse efectiva hasta

\footnotetext{
31) Ibidem.
} 
que tuvieran fondos. Esta decisión real le fue comunicada a Claudio Boutelou el 20 de junio para su divulgación en la Clase de Agricultura ${ }^{31}$. Por su parte, la propuesta de Regás de crear otra Cátedra de Agricultura, o mejor dicho, Escuela Provincial de Agricultura en Alcalá de Henares no obtuvo una respuesta del gobierno porque había alcanzado mayor preminencia el plan que habían presentado a la Secretaría de Estado los hermanos Vicente y Josef Espert para establecer una Escuela Práctica de Agricultura en la Real Casa de Campo. El Duque de San Carlos, Primer Secretario de Estado, pidió a Antonio Siles que le informara «á la mayor brevedad que le sea posible» sobre ese plan. Esa tarea le fue asignada a la Clase de Agricultura el 26 de julio por medio de Claudio Boutelou ${ }^{32}$.

Informe de la Clase de Agricultura sobre el plan de Escuela Agrícola de los hermanos Espert

El informe de la Clase de Agricultura no se hizo esperar. El 9 de agosto de 1814 terminaron su evaluación las nueve personas que intervinieron en el mismo: Antonio Sandalio de Arias, Francisco López de Olavarrieta, Josef de la Serna Lastra, Antonio Regás, Joaquín de la Croix y Vidal, José Pavón, Pedro Regalado de Soto, Agustín Pascual y Claudio Boutelou, quien fungía como Secretario de la Clase.

Además de Arias, las figuras de Pavón, Pascual y Boutelou eran reconocidas en el ámbito de la botánica sin restar mérito a López de Olavarrieta. Dada la calidad de los informantes se garantizó una valoración rigurosa del plan de los Espert. En efecto, la Clase criticó fuertemente ese proyecto a pesar de que era para las autoridades «el mas apropósito».

La simpatía que existía entre algunos funcionarios por la propuesta de los Espert se debía al carácter obligatorio de su enseñanza, ya que se basaba en la recogida de los niños pobres que vagabundeaban por las calles de Madrid. Precisamente, la Clase criticaba esos supuestos «altos fines».

Desde el punto de vista pedagógico la coerción era una cuestión inaceptable para la Clase. Apoyándose en la experiencia de otros establecimientos docentes en Italia, Francia e Inglaterra rechazaba el método que recomendaban los Espert:

«En aquellos [establecimientos extranjeros] se encuentran honor y libertad en fabor de los discípulos qe. voluntariamente quieran aprender tan útil ciencia, en este solo se ve coaccion y violencia hacia ellos, pues recogidos los discipulos de la hez del pueblo, lleba consigo el establecimiento la idea que este mismo hecho produce» ${ }^{33}$.

31 Ibidem

32 A.R.S.E.M., leg.217, expte.7.

3.3 A.R.S.E.M. leg.260, expte.2. 
En opinión de la Clase, tampoco la coerción era favorable para propiciar en los niños vagabundos una vocación por la Agricultura a la que no estaban habituados ya que por su procedencia social debían estar más interesados por las Artes. En todo caso, el destino de esos niños debía hallarse en la milicia y en la marina «como se ha echo en otras ocasiones». Asimismo, consideraba que la mayor de las contradicciones que tenía el plan estaba en la pretensión de mezclar a los hijos de «padres honrados y prudentes» con los jóvenes «mas viciosos y corrompidos de toda la Nacion». En definitiva, se muestra partidaria de una docencia agrícola que fuera ciencia y arte y no un mero «oficio» como el que proponían los Espert al dedicar su proyecto a quienes debían desempeñarse como jornaleros; la Clase tenía la seguridad de que era imposible instruir «al que ara ó caba, pues para estos la agricultura no es mas que un oficio de rutina». Por eso, indicaban que la única manera de mejorar la agricultura dependía de la instrucción teórica y práctica que tuvieran «los hacendados y labradores pudientes» dada la obligación que tenían ellos de convertirse en «los verdaderos maestros practicos de sus criados» si querían atender eficientemente sus propiedades sin necesidad de que estuvieran al cuidado de «sus ignorantes y rústicos domésticos».

Por último, la Clase señalaba que el plan de los Espert carecía de la más mínima condición moral para ser llevada a efecto no solo por su falta de originalidad en cuanto al lugar elegido para establecer la Escuela sino también por otras dos cuestiones:

- Los hermanos Espert no eran los más capaces para desempeñar «dignamente la enseñanza agraria segun corresponde» ya que en su función de jardineros solo tenían el mérito de exceder a los demás en el cultivo de los claveles.

- El plan tomaba como pretexto el «beneficio público» de esa enseñanza agrícola cuando los gastos excesivos en su mantenimiento demostraban que el verdadero propósito era el de la especulación particular.

De acuerdo con los señalamientos expresados, la Clase recomendó al Rey que suspendiera cualquier plan - como el de los Espert - con respecto a la Casa de Campo hasta que no se definiera el plan general de enseñanza agraria que se adoptaría para toda la nación atendiendo que el modelo de cátedra adjunta a los jardines botánicos era permisible si se pudiera llevar a efecto la Real Orden firmada por Carlos IV el 18 de diciembre de 1805 que establecía veinticuatro establecimientos botánicos en toda la península. No obstante, el estado caótico en que quedó el país después de la guerra le permitió a la Clase sugerir - reajustando el criterio expresado por Arias en 1809- la creación de al menos seis Escuelas de Agricultura donde se diera gratuitamente la enseñanza teórica y práctica. Esas Escuelas debían establecerse en las capitales de Andalucía, Extremadura, Galicia, León, La Mancha y las Castillas para atender las necesidades agrícolas de cada territorio. 
Este informe de la Clase de Agricultura fue aprobado por la Junta de la Sociedad el 13 de agosto de 1814, enviándose una copia al Ministerio del Estado el 19 de ese propio mes $^{34}$.

La contrapropuesta al plan de los Espert: el proyecto de escuelas de Arias y Olavarrieta

Esa sugerencia de la Clase de Agricultura de crear seis Escuelas de Agricultura en España como plan alternativo al de los Espert llevaba implícito el compromiso de presentarlo de manera más detallada. Así lo llevó a efecto la comisión integrada por Arias y Francisco López de Olavarrieta al exponer el 21 de octubre de 1814 en la mencionada Clase su informe «sobre la importancia y necesidad de fomentar por todos los medios la enseñanza de Agricultura en varias Provincias del Reyno» ${ }^{35}$.

Ese informe fue discutido en Junta General de la Sociedad del 22 de octubre, recomendándose su reelaboración de acuerdo con las observaciones realizadas.

La versión definitiva se terminó el 27 de octubre con el título «Exposicion que hace la clase de Agricultura a la Rl. Sociedad Economica de Amigos del País de Madrid sobre cátedras y escuelas de Agricultura extendida en virtud de comision» que fue aprobada en Junta General de la Sociedad del día 29 para su remisión al Duque de San Carlos, en su condición de Primer Secretario de Estado ${ }^{36}$.

Los arreglos efectuados al informe estuvieron en función de la parte más importante: la dedicada a los arbitrios que requerirían esos centros docentes. De la comparación entre el borrador del 21 de octubre y el documento definitivo del día 27 se pueden detectar algunas diferencias con respecto a los medios más adecuados para obtener ese financiamiento.

Gran parte del texto del primero de esos medios aparece íntegramente en ambos documentos:

\footnotetext{
«Los propios y arbitrios de todos los pueblos de la Provincia en que se estableciese la Escuela, deben contribuir pa. plantificarla y sostenerla; pues como ellos han de disfrutar mas inmediatamente de los beneficios q. resulten de la Enseñanza, parece justo qe. entre todos suministren los fondos necesarios».
}

De esa forma, se aprecia una plena coincidencia entre ambos documentos por mantener ese punto como la principal fuente de ingresos de las Escuelas salvo unas

34 Ibidem.
35 A.R.S.E.M., leg.217, expte.7.
36 Ibidem.

118 
líneas finales que sólo aparecen en el borrador del día 21 donde se indica que «la Sociedad cree qe. una muy corta consignacion sobre sus productos bastaría para su dotacion».

En segundo lugar, se hace mención en el documento definitivo del día 27 al fondo de los «espolios y vacantes» del Estado que podía ser destinado para las Escuelas, redactándolo en unos términos donde apenas se aprecian variaciones con respecto al original. La única diferencia con el primer escrito estaba dada en el orden de prioridades que ocupaba entonces que era el tercero.

La tercera fuente de ingresos que se menciona en el informe final del 27 aparecía en el documento inicial del 21 redactado en el margen del texto y ocupando un cuarto lugar. Se trataba de los diezmos de la Iglesia:

«La masa total de diezmos, es en concepto de la Clase el recurso mas seguro y el fondo mas análogo pa. el objeto de que se trata y del qual debería sacarse lo necesario para estas Escuelas, pues es bien cierto, qe. á proporcion que se adelante y perfeccione la agricultura, será mayor el ingreso de este fondo, y el estado Ecleciastico lejos de disminuir sus rentas por esta exaccion las aumentará considerablemente. Tambien podrian dotarse estos establecimientos con algunas pensiones sobre Mitras vacantes, ó con la reunion de algunos beneficios simples».

Estas fueron las vías de financiamiento que más se destacaban en el documento definitivo del día 27 , al dejar como nota final la parte dedicada a los terrenos baldíos que había sido incluída en la cuarta posición del original ${ }^{37}$. En definitiva, la diferencia más notable entre ambos escritos estaba en la total omisión de un impuesto que aparecía como el segundo más importante del informe del día 21 , el cual afectaba a aquellas provincias que se dedicaban a la actividad comercial marítima al establecer la imposición de «un pequeño recargo á los derechos que pagan los frutos y géneros de importacion».

A excepción de las enmiendas y omisiones realizadas sobre el financiamiento de las escuelas, el resto del texto en ambos documentos se mantuvo inalterable.

Otra parte del informe de Arias y Olavarrieta estuvo dedicado a destacar la necesidad de priorizar la recuperación de la Cátedra de Agricultura que había funcionado en el Real Jardín Botánico de Madrid desde 1807, atendiendo al renacimiento de las lecciones públicas de botánica a cargo de Mariano Lagasca. La Cátedra de Agricultura debía desempeñar, de acuerdo con su nivel científico, un papel activo en la crea-

37 En ese sentido, los terrenos baldíos eran considerados como un «fondo de riqueza existente en todas partes» debido a que «arrendados en cantidad suficiente, ó enagenados en enfiteusis y aplicando todos sus productos inclusos los diezmos como novales, podran ser parte de la dotacion o rendir lo necesario pa. dotar las escuelas de que se trata». Ibidem. 
ción de las seis Escuelas agrícolas que había previsto la Clase de Agricultura al evaluar el plan de los Espert el 9 de agosto ${ }^{38}$.

Uno de los aspectos más interesantes en el mencionado informe sobre el establecimiento de las Escuelas de Agricultura estaba íntimamente relacionado con el proyecto que había presentado Arias en 1809. Se trataba de la labor que aún se le concedía a:

\footnotetext{
«(...) las Sociedades Económicas de los Pueblos en qe. se establezcan, y qe. estas mismas corporaciones al paso que auxilien con sus luces al Catedrático y contribuyan con sus premios é influencia al mayor lustre del Establecimiento, y á la instruccion gl. del labrador (...) reciban y administren los fondos destinados á las Escuelas».
}

Sin embargo, se aprecia que en 1814 había una mayor comprensión para evitar que las cargas administrativas afectaran la labor docente «pues los profesores no deben jamas tener á su cargo la recaudacion ni el manejo de los caudales (...) deberan estar enteramente aislados al objeto esclusivo de la enseñanza» ${ }^{39}$. El esfuerzo de Arias y de Olavarrieta en nombre de la Clase de Agricultura obtuvo el resultado apetecible a pesar del cambio de actitud que asumiera Fernando VII el 3 de noviembre de 1814 al dar a conocer su decisión de borrar de las listas de la Sociedad Matritense a «todos los que han seguido al partido afrancesado» ${ }^{40}$.

Ese resultado se apreció el 6 de febrero de 1815, cuando el Secretario de la Clase de Agricultura Claudio Boutelou recibió del Secretario de la Sociedad la Real Orden de 31 de enero de ese mismo año donde se señalaba que, de acuerdo con las «sabias y juiciosas reflexiones» de los Amigos del País se había determinado que el plan de los hermanos Espert no se llevara a efecto y que, en su lugar, había aprobado el establecimiento de seis cátedras de Agricultura en las provincias de Castilla la Nueva, Castilla la Vieja, Andalucía, Extremadura, Galicia y León, asignándole a cada una 20 mil reales de vellón que debía pagarse de «los Propios y arbitrios de las respectivas Provincias». De esa cifra el catedrático debía disfrutar de 12 mil reales de vellón mientras que los restantes 8 mil serían para los gastos de enseñanza y labores del terreno, En esa decisión real se incluía una solicitud a la Matritense para que se en-

38 Esa aspiración se haría realidad el 8 de abril de 1815 cuando el propio Arias inaugure esa enseñanza como catedrático de la misma. Sandalio de Arias, A. (1818), «Discurso pronunciado en la Cátedra de Agricultura al abrir el curso de estas Lecciones, el día 8 de Abril de 1815, á presencia del Rey Nuestro Señor y de los Serenísimos Señores Infantes Don Carlos y Don Antonio», en Sandalio de Arias, A., Lecciones de Agricultura esplicadas en la cátedra del Real Jardín Botánico de Madrid el año de 1815, Imp. de Fuentenebro, Madrid, $2^{a}$ ed. corregida y aumentada por el autor, t. I, pp.XXVII-XXIII.

39) Ibidem.

41) GonzÁlez Echegaray, C. (1993), p.181. 
cargara de la confección de un Plan o Reglamento de enseñanza para esas Escuelas, tarea que debía efectuar la Clase de Agricultura. Ese Reglamento fue escuchado favorablemente en Junta de la Sociedad de 18 de febrero acordándose su envío al Secretario de Estado Pedro Cevallos.

No fue hasta el 2 de octubre cuando Antonio Sandalio de Arias recibió, como Secretario interino de la Clase de Agricultura, la Real Orden de 27 de septiembre donde se confirmaba la aprobación del Reglamento de las Escuelas y se le pedía a la Sociedad la confección y publicación de la convocatoria para las oposiciones a las plazas de profesor. También se señalaba que los miembros de la Clase de Agricultura serían los jueces en esas oposiciones bajo la presidencia del Director de la Sociedad.

La Sociedad Económica trató el 18 de octubre de que el Rey aprobara rápidamente la minuta del anuncio que convocaba las oposiciones para el primero de enero de 1816; sin embargo, en esa fecha aún no se había recibido una respuesta autorizándolo. Unos meses después, el 24 de junio de 1816, el impaciente Arias logró que la Matritense elevara una representación para que se tuviera en cuenta esa situación ${ }^{41}$. Hubo que esperar hasta la Real Orden del 26 de noviembre de 1818 para recibir el encargo de publicar la convocatoria a las oposiciones. La Clase de Agricultura presidida por Arias - dio a conocer como fecha de realización de esos ejercicios el primero de marzo de 1819. Sin embargo, hubo que posponerla nuevamente por gestiones en la prestación de una sala para la realización de los ejercicios orales y en la autorización de la Junta de Protección del Museo de Historia Natural para efectuar los ejercicios prácticos en el Jardín Botánico ${ }^{42}$. En definitiva, las oposiciones se realizaron entre el 9 de marzo y el 2 de abril de 1819 en una sala del Real Colegio de Sordomudos y en el Jardín Botánico. De las doce personas que se presentaron, le correspondieron a Francisco Martínez Robles, a José Lucio Pérez, a Pascual Asencio, a José Alonso Quintanilla, a Julián de Luna y a Francisco Gil Rodríguez las cátedras de Toledo, Sevilla, Burgos, León, Badajoz y Valencia, respectivamente ${ }^{43}$. Todo parece indicar que estas cátedras empezaron a sistematizar su labor docente en el segundo trimestre de 1820. Sin embargo, dejaron de funcionar con la restauración de la legislación vigente en el anterior período liberal. Existía el ánimo de reajustar la organización de esas cátedras al contenido del decreto de las Cortes del 8 de junio de 1813.

41 Ibidem.

42 A.R.S.E.M., leg. 274 , expte.2.

4. A.R.S.E.M., leg.279, expte.33(a), y leg.279, expte.34(a). 